\title{
MORBIDITY IN THE INSURED POPULATION OF NORTHERN IRELAND
}

\author{
BY \\ A. T. PARK AND C. W. KIDD \\ From the Ministry of Finance \\ and the Ministry of Health and Local Government, Belfast, N. Ireland
}

A committee of inquiry known as the Tanner Committee (1955), set up by the Government of Northern Ireland to survey the Health Services, stated in their comment on the relatively high cost to the National Insurance Fund of sickness in the insured population: "It may be that there is a greater incidence of illness in Northern Ireland than in other parts of the United Kingdom".

This speculation has been made on many occasions as it is a fact that since the inception of sickness benefit schemes an appreciably higher relative expenditure has been experienced in Northern Ireland than in Great Britain.

In the absence of any complete morbidity data or reasonably representative samples of such data in the United Kingdom, it is impossible to prove or disprove any generalizations on community ill-health. It is felt, however, that a general survey of some statistical data available to us, with, where possible, comparisons between our figures and those published in other parts of the United Kingdom, may be of interest. The amount and duration of sickness in the insured population will be considered together with an estimate of the size of the chronic and longterm sickness problem.

Definitions.-Those recommended in the Report of the Statistics Sub-Committee of the Registrar General's Advisory Committee (General Register Office, 1954) have been followed with the following additions:

(a) Long-term Sickness-spells of incapacity of more than 1 years' duration.

(b) Chronic Sickness-spells of incapacity of more than 2 year's duration.

(c) Other Women-single, widowed, and divorced women.

UNEMPLOYMENT.-The Province suffered severely from the depression in the early 1930s, and for a few years one in four of the insured population was unemployed. The position has greatly improved since 1945 with the introduction of new industries and the high level of employment in Great Britain but, despite this, unemployment is heavy in comparison with the rest of the United Kingdom. The average percentage unemployed in 1956 was 6.4 per cent. of insured employees compared with $1 \cdot 2$ per cent. in Great Britain.

Unemployment in Northern Ireland is subject to violent seasonal fluctuations: in 1956 for instance, the October figure of 25,309 was some 13,000 lower than the January figure and this is typical of the trend each year.

There is also an appreciable regional variation in the level of unemployment, the unemployment rate in the Belfast conurbation being much lower than in such areas as Newry, Enniskillen, and the surrounding rural districts.

A great deal of publicity is given to the large number of persons registered as unemployed in Northern Ireland, but little reference is made to the number absent from work because of sickness The number on the sickness register has never fallen below 30,000 since the inception of the National Insurance Schemes in 1948.

Numbers EXPOSEd To RisK.-In general all employees and self-employed persons between schoolleaving age and the date of retirement are insured against sickness, the main exceptions being those married women who elect not to pay contributions and those self-employed persons who claim exemption on the grounds that their income calculated in accordance with the requirements of the Act is less than $£ 156$ a year.

In addition, special conditions in the regulations governing sick pay of the civil service and police have the result that the Ministry of Labour and National Insurance has no direct information about morbidity in these employments and they, together with members of H.M. Forces, have been excluded from all the data that follow.

Under the National Insurance Act (Northern Ireland) 1946, persons with the appropriate insurance qualifications are entitled to claim sickness 
benefit for periods during which they are "incapable of work by reason of some specific disease or bodily or mental disablement". Persons who are not entitled to benefit because they have exhausted their rights or have insufficient contributions to their credit to qualify, may present evidence of incapacity for work to secure release from the obligation to pay weekly contributions, and to be credited with a contribution instead for each complete week throughout which the incapacity has continued. Applications of this kind for "credits" are recorded in the same way as claims to benefit. Spells of incapacity lasting less than 4 days do not usually attract sickness benefit or credit and, therefore, are commonly not reported.

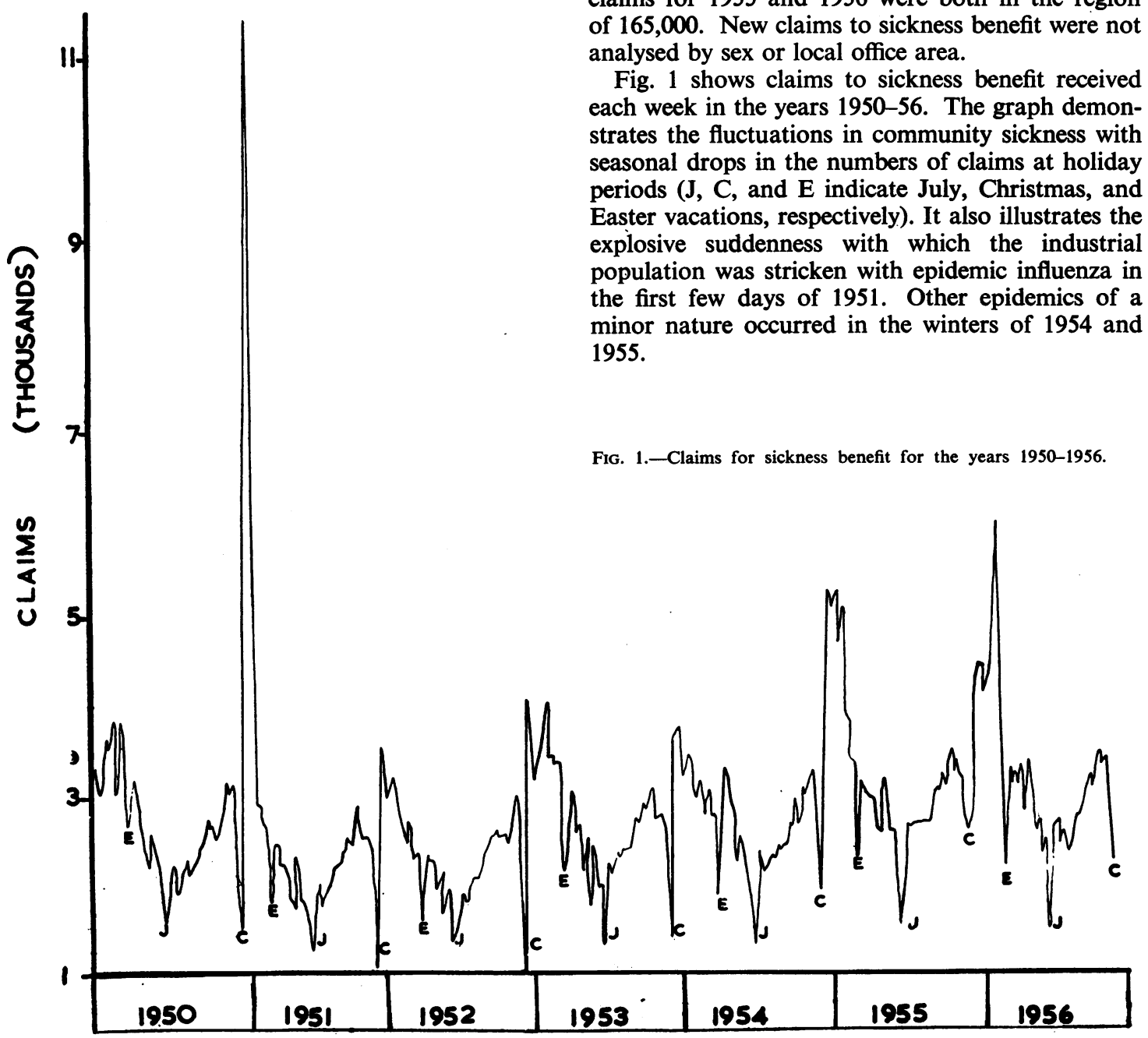

When we exclude members of the Forces, civil servants, and police, there are approximately 505,000 persons covered for sickness benefit in Northern Ireland. The approximate sex distribution is 340,000 men and 165,000 women $(35,000$ married and 130,000 other women). These numbers represent about 80 per cent. of the males and 40 per cent. of the females in the corresponding age groups in the population of the Province.

New Claims Experience.-In 1949, the first full year of the new schemes, there were 120,000 claims to sickness benefit, in each of the next 2 years 140,000 claims, in 1952120,000 , and in each of the following 2 years again 140,000. Unfortunately, this pretty series has not been maintained and the claims for 1955 and 1956 were both in the region of 165,000 . New claims to sickness benefit were not nalysed by sex or local office area.

received seasonal drops in the numbers of claims at holiday periods ( $\mathrm{J}, \mathrm{C}$, and $\mathrm{E}$ indicate July, Christmas, and Easter vacations, respectively). It also illustrates the explosive suddenness with which the industrial population was stricken with epidemic influenza in first few days of 1951. Other epidemics of a minor nature occurred in the winters of 1954 and 1955 strates the fluctuations in community sickness with 
Regional VARIATION.-The regional aspect of sickness can be examined in more detail from a count of all current cases in receipt of sickness benefit or credit. As a result of such a count at the end of August, 1955, when there were 36,000 persons incapacitated through sickness, it was estimated that the point prevalence rate was $7 \cdot 1$ per cent. of the population exposed to risk- $6 \cdot 2$ per cent. for men and 9.0 per cent. for women (it was not possible to separate the married women from the others). It is very difficult to calculate the numbers exposed to risk in each local office area, but so far as we can estimate the point prevalence rate was 10 per cent. or higher in the following areas: Newry, Dungannon, Enniskillen, Omagh, Magherafelt, Cookstown, Armagh, and Ballymoney. These are mostly agricultural areas where seasonal unemployment is a major problem.

Limitations of DatA.-The available statistics on diagnosis are of a secondary nature in that they were compiled initially for the Government Actuary who makes annual and quinquennial reviews of the National Insurance scheme. They are based on the sickness experience of 20 per cent. of the persons incapacitated and, while this sample may be sufficient for actuarial purposes, when it is broken down into small subdivisions, such as by age, sex, and diagnostic sub-groups necessary for any morbidity study, the figures must be treated with considerable reserve. The figures have been confined to ages 15-64 for men and 15-59 for women except in the comparisons with Scotland.

The nature of the incapacity has been obtained from the diagnosis given by the medical practitioner on the last medical certificate received by the Ministry of Labour and National Insurance; where this diagnosis is not explicit (for example, "convalescence" or "debility") the last preceding diagnosis that it sufficiently specific has been used. The diagnosis has been coded according to the International Statistical Classification of Disease (1948) and the diagnoses have been grouped into the eighteen cause groups originally used in the quarterly reports on the sickness surveys carried out by the Social Survey and published in the quarterly return of the Registrar General for England and Wales.

INCEPTION RATES.-The number of spells of sickness which started during the year per 1,000 persons exposed to risk are shown in Table I.

Fig. 2 shows the inception rates for men, married women, and other women by age groups averaged
TABLE I

NUMBER OF SPELLS OF SICKNESS STARTING DURING EACH YEAR, PER 1,000 PERSONS EXPOSED TO RISK, BY SEX

\begin{tabular}{c|c|c|c}
\hline \multirow{2}{*}{ Year } & \multirow{2}{*}{ Men } & \multicolumn{2}{|c}{ Women } \\
\cline { 3 - 4 } & & Married & Other \\
\hline 1950 & 219 & 558 & 263 \\
1951 & 248 & 560 & 290 \\
1952 & 209 & 447 & 225 \\
1953 & 235 & 550 & 252 \\
1954 & 229 & 543 & 250 \\
1955 & 267 & 597 & 312 \\
\hline
\end{tabular}

over the 6 years $1950-55$ inclusive. As the number of married women exposed to risk in each age group is small, their rates should be treated with caution.

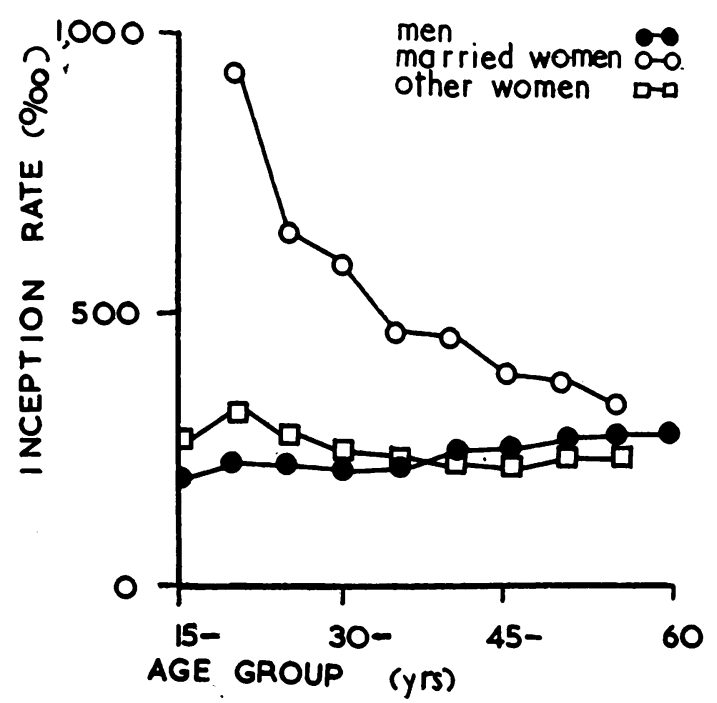

Fig. 2.-Inception rates (spells of sickness) per 1,000 exposed to risk, by age group and sex.

Amongst men there appears to be a slight but definite positive correlation between age and inception rate after age 30 . There is a marked negative correlation for married women from the exceptionally high rates at child bearing ages, but, at all ages, the rate for married women is appreciably higher than for other women. The fact that the inception rate for other women falls with age may in some measure be due to only the more robust women remaining in the working population in the older age groups.

Table II (overleaf) gives the inception rates per 1,000 insured for each of the eighteen diagnostic groups for each year 1950-55 in the sex and marital status groups. In the working population there is a higher inception rate for psychoneurosis amongst married women than amongst other women and men. 
TABLE II

INCEPTION RATES ACCORDING TO DIAGNOSIS; SHOWING NUMBER OF SPELLS OF SICKNESS PER 1,000 EXPOSED TO RISK, BY SEX, 1950-1955

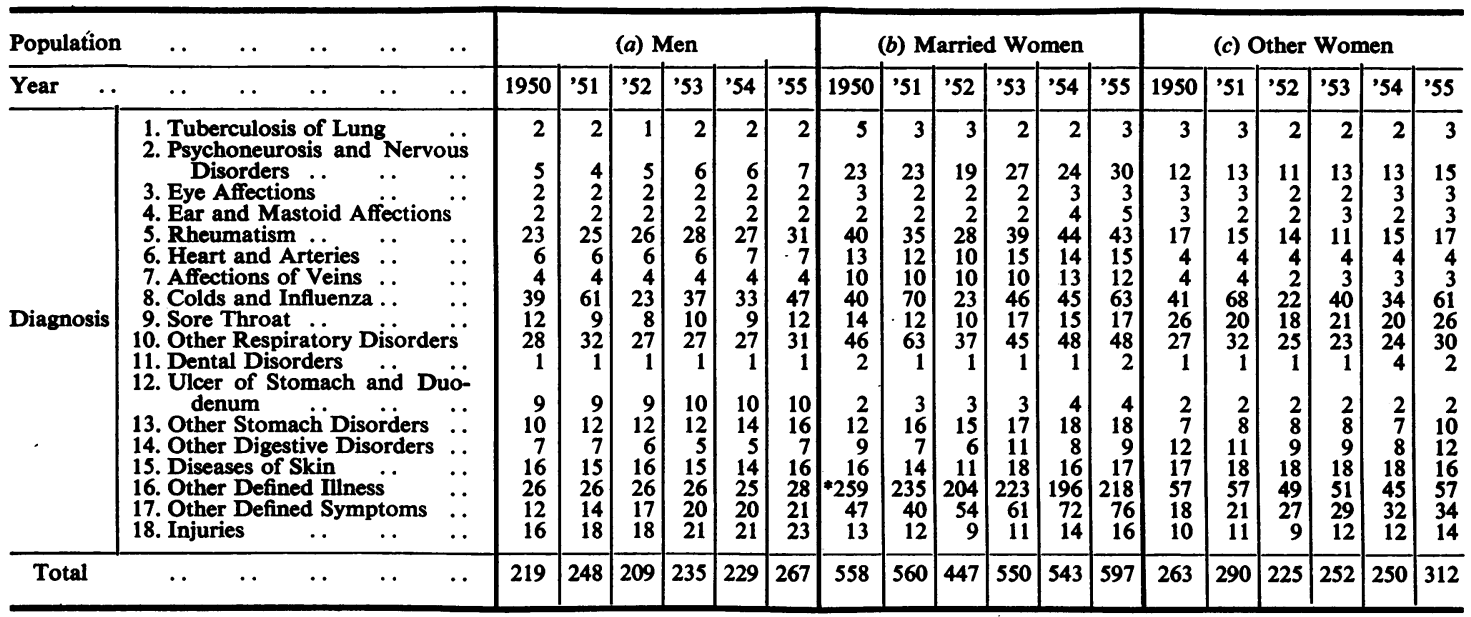

* Including pregnancy.
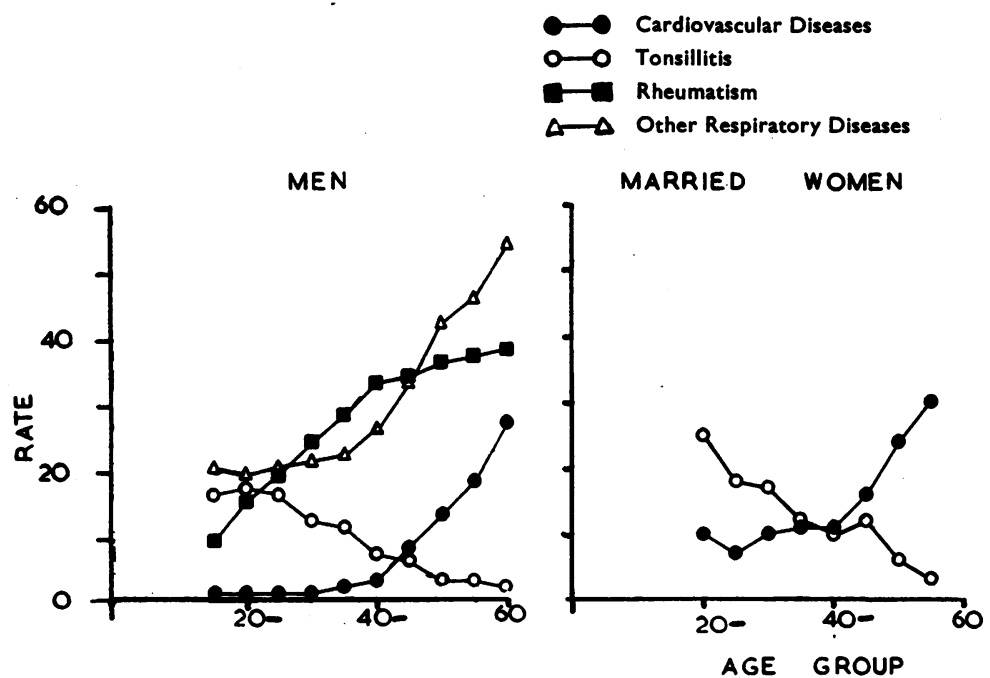

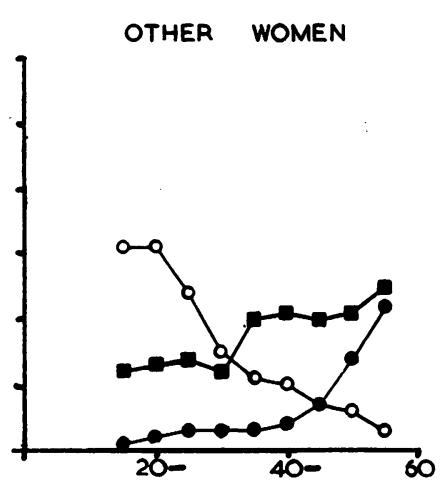

Fro. 3.-Inception rates (spells of sickness), by age group and sex for cardiovascular disease, tonsillitis, rheumatism, and other respiratory diseases.

Rheumatism also is more frequent amongst married women than amongst men and other women. Ulcers of the stomach and duodenum are more common amongst men. The exceptionally high rate for married women in the "other defined illness". group is due to the inclusion of pregnancy in this group.

Fig. 3 shows average inception rates for certain diagnoses for the years 1950-55 according to age: (a) Men, (b) Married Women, (c) Other Women. These graphs show for each class the diagnoses where there is a marked correlation between inception rates and age.
FrequenCY OF SPELLS OF ILLNESS.-It is estimated that, amongst the insured population covered for sickness, about 21 per cent. of the males, 50 per cent. of the married women, and 22 per cent. of the other women have at least one spell of sickness absence during the year. Of the 71,000 men who had spells of sickness absence starting in 1955 , i.e. including those sick throughout the year, 57,000 had only one spell, 11,000 two spells, and 3,000 more than two spells, the maximum number of spells being eight. Of the 16,500 married women who had spells starting in $1955,12,500$ had only one spell, 3,000 had two 

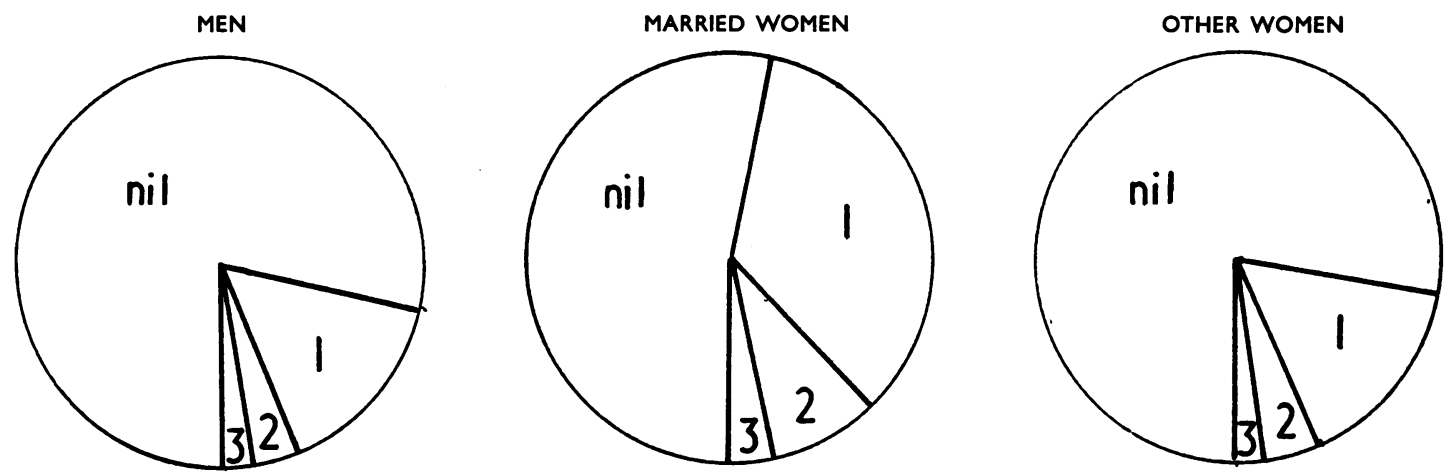

Fig. 4.-Frequency of spells of sickness, by sex. The segment marked 3 includes three spells of sickness and over.

spells, and 1,000 more than two spells, the maximum number of spells being six. Of the 28,000 other women who had spells starting in $1955,22,000 \mathrm{had}$ only one spell, 5,000 had two spells, and 1,000 had more than two spells, the maximum number of spells being six. These frequencies are illustrated in Fig. 4 (above).

Comparisons With Scotland.-It is of interest to compare this experience with other areas in the United Kingdom so that evidence can be accumulated for or against the suggestion that Northern Ireland has "abnormally high" sickness rates. It is known from published figures that, whereas the inception rate of spells of sickness is lower in Northern Ireland than in Great Britain, the point prevalence rate is consistently higher. The comparison of the experience in Northern Ireland with that in Great Britain is obviously not a comparison of like with like, and for that reason we investigated the possibility of obtaining details of the sickness experience in one of the regions in Great Britain which would be more akin; we were able to obtain sickness statistics for the year ended 5 June, 1954, based on a 5 per cent. sample for Scotland, but unfortunately the only available details of those exposed to risk in Scotland is that for males in total; no age analysis is available nor even an overall figure for females.

The Scottish figures were analysed according to the Special List of fifty causes with certain extensions, and a similar analysis of the Northern Ireland data resulted in the following comparison:

For the number of new incapacities commencing within a year, it was found that the inception rate for males for Scotland was 334 per 1,000 insured against 252 for Northern Ireland. Table III shows a comparison of the inception rates for some of the more frequent diagnoses. Except for influenza, the Scottish rates were always the higher, but, of course,
TABLE III

NEW INCAPACITIES COMMENCING WITHIN THE YEAR, MALES

\begin{tabular}{|c|c|c|c|c|}
\hline \multirow{2}{*}{\multicolumn{2}{|c|}{ Diagnosis }} & \multicolumn{3}{|c|}{$\begin{array}{c}\text { Inception Rates (Spells) per } 1,000 \\
\text { exposed to Risk }\end{array}$} \\
\hline & & Scotland & Northern I & Ireland \\
\hline $\begin{array}{l}\text { Common Cold } \\
\text { Acute Tonsillitis } \\
\text { Influenza } \\
\text { Bronchitis } \quad . \\
\text { Gastritis } \\
\text { Cellulitis } \\
\text { Rheumatism } \\
\text { Sprains and Strains. }\end{array}$ & $\begin{array}{l}\cdots \\
\cdots \\
\cdots \\
\cdots \\
\cdots\end{array}$ & $\left.\begin{array}{l}10 \\
15 \\
42 \\
28 \\
14 \\
10 \\
25 \\
9\end{array}\right\} 153$ & $\left.\begin{array}{r}3 \\
8 \\
45 \\
22 \\
12 \\
6 \\
24 \\
5\end{array}\right\}$ & 135 \\
\hline All Causes & $\cdots$ & 334 & 252 & \\
\hline
\end{tabular}

this might be a function of differencies in the age distribution of the two populations.

With the long-term cases, i.e. those incapacitated throughout the year under review, the position is reversed. In Scotland 16.2 males out of every 1,000 exposed to risk had been ill continuously for at least one year while the corresponding figure for Northern Ireland was $25 \cdot 8$. Table IV shows a comparison of these rates for some of the more frequent diagnoses for males. Except for "psychosis", the

TABLE IV

INCAPACITIES LASTING AT LEAST ONE YEAR, MALES

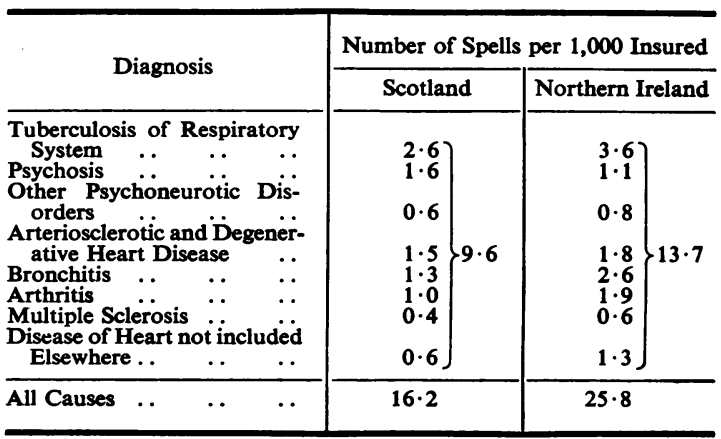


Northern Ireland rates were always the higher, but again the age effect cannot be taken into account.

The marked difference in the figures for bronchitis and arthritis is notable; there is no apparent explanation for this difference in the experience of the two countries.

Chronic Sickness in Northern Ireland.-In the case of Northern Ireland we were able to assess the magnitude of the chronic sick problem. Approximately one-third of the claimants on the sickness register have been continuously incapacitated for at least 2 years. In terms of those exposed to risk, 18.8 per 1,000 insured males were chronic cases; the corresponding figure for married women was 58.4 and for other women $23 \cdot 5$. The age distribution of those chronic cases is given in Table V.

TABLE V

AGE ANALYSIS OF CHRONIC SICK AMONGST INSURED POPULATION IN NORTHERN IRELAND AT MAY 31, 1955

\begin{tabular}{|c|c|c|c|c|c|c|}
\hline \multirow[b]{3}{*}{$\underset{\substack{\text { (yrs) } \\
\text { Aroups }}}{\text { Age }}$} & \multirow{2}{*}{\multicolumn{2}{|c|}{ Men }} & \multicolumn{4}{|c|}{ Women } \\
\hline & & & \multicolumn{2}{|c|}{ Married } & \multicolumn{2}{|c|}{ Other } \\
\hline & Number & $\begin{array}{c}\text { Per } \\
1,000 \\
\text { Insured }\end{array}$ & Number & $\begin{array}{c}\text { Per } \\
1,000 \\
\text { Insured }\end{array}$ & Number & $\begin{array}{c}\text { Pet } \\
1,000 \\
\text { Insured }\end{array}$ \\
\hline \multirow{2}{*}{$\begin{array}{c}\text { Under } 20 \\
20-29 \\
30-39 \\
40-49 \\
50-59 \\
60 \text { and } \\
\text { Over }\end{array}$} & $\begin{array}{r}35 \\
325 \\
740 \\
1,210 \\
2,470\end{array}$ & $\begin{array}{r}\overline{4 \cdot 7} \\
10 \cdot 0 \\
16 \cdot 3 \\
40 \cdot 1\end{array}$ & $\begin{array}{l}\overline{245} \\
360 \\
510 \\
930\end{array}$ & $\begin{array}{r}\overline{21 \cdot 3} \\
40 \cdot 0 \\
56 \cdot 7 \\
143 \cdot 1\end{array}$ & $\begin{array}{r}45 \\
430 \\
525 \\
780 \\
1,275\end{array}$ & $\begin{array}{l}\overline{11 \cdot 2} \\
35 \cdot 0 \\
60 \cdot 0 \\
91 \cdot 1\end{array}$ \\
\hline & 1,615 & $73 \cdot 4$ & - & - & 5 & - \\
\hline Total & 6,395 & $18 \cdot 8$ & 2,045 & $58 \cdot 4$ & 3,060 & $23 \cdot 5$ \\
\hline
\end{tabular}

Note: Owing to the small numbers of married women in the older age groups these rates should be treated with reserve.

FURTHER COMPARISONS WITH SCOTLAND.-The third group of cases in which a reasonable comparison with Scotland was possible comprised those terminating during the year under review. In this case it was possible to analyse for both males and females according to duration within each diagnostic group. For all causes the median duration for males was 13 days in Scotland and 18 days in Northern Ireland; for females the median was 16 days in Scotland and 19 days in Northern Ireland. When the figures are broken down by diagnosis it cannot too strongly be stated that owing to the size of the sample and the distribution of the durations the estimated median shown may differ considerably from the true median for a particular group, but Table VI includes only diagnoses wherein these effects do not appear to make the comparisons between the countries invalid. Table VI shows that the longer durations in Northern Ireland are not confined to any one group of illness but occur in practically every diagnostic group in the Table. Arthritis merits a much longer period of incapacity in Northern Ireland for both sexes, as does asthma in males and hypertension in females. Coronary disease requires longer for recuperation and even the common cold and tonsillitis require a longer period in both sexes in Northern Ireland.

TABLE VI

COMPARISON OF MEDIAN DURATIONS (IN DAYS) FOR CERTAIN DIAGNOSIS BETWEEN SCOTLAND AND NORTHERN IRELAND

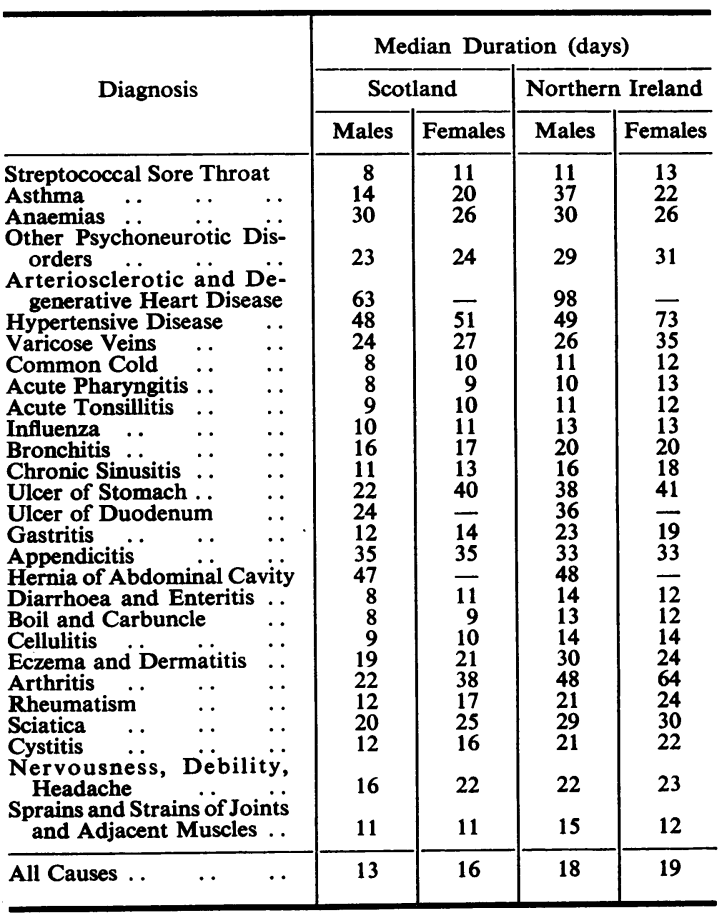

\section{Discussion}

It is difficult to explain why morbidity experience in Northern Ireland should be so notably different from that in Scotland. The inhabitants of Northern Ireland participate fully in all benefits of the Welfare State, and it cannot be accepted that there is any fundamental, physical, hereditary, environmental, or climatic differences between them and their neighbours. It can be said that, broadly speaking we are comparing like with like in terms of these factors.

From a statistical point of view, if it is a fact that more new sickness claims of a trivial nature are made in Scotland, then it follows that the average duration of sickness will be shorter in that country. 
The lower rate for new claims in Northern Ireland suggests that there is less sickness or less desire to "go sick", or more reluctance on the part of doctors to issue initial certificates of incapacity for minor illnesses. None of these are satisfactory explanations.

Longer durations of sickness in Northern Ireland suggest that sickness when it comes is more severe and incapacitating, and that doctors are either more careful about returning their patients to work after illness or, having given a certificate of incapacity, more lax in determining its conclusion. It is probable that a mixture of these possibilities operate and it is difficult to exclude lax certification as a factor.

The extent of semi- and permanent invalidism is a grave aspect of the local problem. It represents considerable human misery and at the same time imposes a serious financial burden on the National Insurance Fund. A study of the specific conditions giving rise to long-term and chronic sickness may well produce interesting results.

\section{SUMMARY}

(1) This study was instigated by the knowledge that, on a basis of annual cost to the National Insurance Fund, ill health in a selected population in Northern Ireland is greater than that experienced in the rest of the United Kingdom.

(2) A survey of certain aspects of morbidity in the insured population of Northern Ireland has been made from data compiled under the National Insurance Scheme.

(3) Where valid comparisons are possible between records of sickness in Scotland and Northern Ireland, such comparisons have been made.

(4) New claims to sickness benefit are made less frequently by men in Northern Ireland than in Scotland.

(5) The duration of sickness claims is on average longer in both sexes in Northern Ireland than in Scotland and this difference is relatively more important among men and for certain diagnoses.

(6) There is much more long-term sickness among men in Northern Ireland than in Scotland.

We are most grateful to Dr. P. J. McKinlay, Department of Health for Scotland, who has provided us with statistical material, to Dr. E. A. Cheeseman, Department of Social and Preventive Medicine, Queen's University, Belfast, for his advice and help, and to the Chief Medical Officer, Ministry of Health and Local Government, for permission to publish this paper.

\section{REFERENCES}

General Register Office (1954). “Measurement of Morbidity". A Report of the Statistics Subcommittee of the Registrar General's Advisory Committee on Medical Nomenclature and Statistics. Studies on Medical and Population Subjects, No. 8. H.M.S.O., London.

Tanner Committee (1955). "Ministry of Health: Report of the Committee on the Health Services in Northern Ireland". H.M.S.O., Belfast. 